\title{
Chestnut: from coppice to structural timber. The case study of "Uso Fiume" beams sampled in Liguria
}

\author{
Marco Togni, Alberto Cavalli, Davide Mannozzi \\ GESAAF - Dipartimento di Gestione dei Sistemi Agrari, Alimentari e Forestali, Università di \\ Firenze, Italy
}

\begin{abstract}
Recently Agriculture Department of Liguria Region had supported studies and researches on the timber quality of living trees in local coppice chestnut forests, with the prospect to produce also timber for structural use. Under some $a d$-hoc funds a 30 years old coppice forest in the high Bormida Valley, never thinned after the last utilization, has been chosen for sampling. 18 selected trunks were felled and the assortment called "Uso Fiume" (UF) was chosen, getting 49 beams (cross-section from $12 \times 12$ to $24 \times 24 \mathrm{~cm}$ ), by way of saw-mill operations The UF-beam is a structural element, derived from Italian tradition. Such elements are used in Italian buildings over the time, in substitution to structural sawn timber, principally for roofing. The UF-beam is a square edged log with wane; more precisely it is a full log, edged on four sides, maintaining boxed heart and an approximately central pith. Today the features of such a beam is established according to the specific Italian standard UNI 11035-3 for spruce and fir and to the CUAP (Common Understanding of Assessment Procedure) n. 03.24/22 for chestnut and conifers. The beams were visually graded according to the Visual Strength Grading procedure and the physical and mechanical properties (density, modulus of elasticity-MOE and modulus of rupture-MOR) were determined according to the standard requirements (EN 408, EN 384, ISO 3131), disregarding the moisture content: the mechanical tests were performed with wood in green state (moisture content M.C.>30\%) because it is the actual condition of use in build-
\end{abstract}

Correspondence: Marco Togni, Alberto Cavalli, Davide Mannozzi, GESAAF Dipartimento di Gestione dei Sistemi Agrari, Alimentari e Forestali, Università di Firenze, Italy.

Key words: chestnut, structural timber, square edged log with wane, strength, grading.

Contributions: the authors contributed equally.

Conflict of interests: the authors declare no potential conflict of interests.

Funding: the research was supported by a fund of Regione Liguria Dipartimento Agricoltura, Turismo e Cultura Servizio Politiche della Montagna e della Fauna Selvatica

(C) Copyright M. Togni et al., 2013

Licensee PAGEPress, Italy

Journal of Agricultural Engineering 2013; XLIV(s2):el

doi:10.4081/jae.2013.s2.e1

This article is distributed under the terms of the Creative Commons Attribution Noncommercial License (by-nc 3.0) which permits any noncommercial use, distribution, and reproduction in any medium, provided the original author(s) and source are credited. ing, due to the very low permeability of the chestnut heartwood which entails long seasoning time of large cross section beams. The study showed very high yields considering the stems-to-beams volume ratio, close to $70 \%$. Characteristics values of the sample resulted: char. density $\mathrm{kg} / \mathrm{m}^{3}$, char. modulus of elasticity $E_{0, \text { mean }} 10,3 \mathrm{GPa}$ and char. bending strength $f_{m, k} 28,5 \mathrm{MPa}$. These results can be considered very promising because the data match the Strength Class D24 (EN 338), the same Class as full cross-section chestnut beams (at M.C. $=12 \%$ ).

\section{Introduction}

Liguria is the most forested region in Italy with a forested surface of $62.6 \%$ - 71,5\% according to different inventory assessments. ${ }^{1,2}$ The second inventory, ${ }^{2}$ states that chestnut forests cover around 60000 hectares equal to the $16 \%$ of the regional forests. Recently some public institutions of Liguria, particularly the Mountain Policies Service (Agriculture Department), had supported studies and researches on the timber quality, beginning from living trees. One of the most important species studied was chestnut (Castanea sativa Mill.) whose silvicultural practice is typically coppice.

Since 2010 in Italy it is possible to utilize Chestnut timber with rectangular cross section as visual strength graded structural material. Standard EN 1912:2012, ${ }^{3}$ that allocates each visual grade of the structural timber into the Strength Classes listed in EN 338:2009, ${ }^{4}$ enumerates also Italian chestnut among the different structural timbers.

Near to this kind of structural element, there is a customary Italian product called Uso Fiume (UF): the UF-beam is a structural element, coming from tradition and used in Italian buildings over the time, in substitution to typical structural sawn timber; today it is described as a strength graded product, used as structural timber, "square edged logs with wane" that is "full logs which are edged on four sides maintaining boxed heart and an approximately central pith". 5 This type of products is favoured for rural building, easy to be prepared in self-production and in case of owned forest. But the European standard framework does not yet allow the use of not squares edged beams. Due to this reason, for the use in building of such a structural element, since 2010 a new Italian standard ${ }^{6}$ (for Norway spruce and fir beams), and a specific CUAP 03.04/22 ${ }^{5}$ (for conifers and chestnut) have been developed and approved.

In addition it must be remembered that the better mechanical properties of roundwood in comparison to square sawn wood (rectangular cross section) are well known. ${ }^{7}$ The UF-beams can be considered an intermediate solution between round wood and sawn timber; hence it is expected for its mechanical characteristics as well for the easiness to use in building (compared to the totally roundwood).

To concretize this idea some Italian private firms in a consortium, co-ordinated by an association that represents primary processing and wooden constructions industries, funded a specific research for the implementation of the use also of UF chestnut by means of an 
European Technical Approval (ETA). The document ETA-12/0540 gives to the Consortium (not including companies of Liguria region) the possibilities to use the CE marking for chestnut UF-beams, visually strength graded for structural use.

For the chestnut from coppice sampled in Liguria, the aims of the research, strictly regarding the structural use of wood, were:

- the study on relationship between quality of the standing trees and final use,

the determination of characteristic values used for the structural design,

the comparison with known values of square edged beams of the species,

the assessment of the suitability of the combination species/origin/ product to the proposed use.

Final objective is the promotion of this timber as structural material and so the enhancement of the utilise.

\section{Materials and methods}

A 30 years old coppice forest in the high Bormida Valley, growth in high soil fertility, never thinned after the last utilisation, was chosen for the sampling. Some standing trees were selected following the principles of the cutting diameter (min. $20 \mathrm{~cm}$ ) and the stem straightness (max. curvature $1 \mathrm{~cm} / \mathrm{m}$ stem length). No other criterion was chosen for selecting, but all the visible defects were evaluated, to assess the log quality finalized to structural use, following a specific protocol, including also: the ratio between largest branch and stem diameters at the insertion point, the presence/absence of injury on the bark or signs of disease on living tree (e.g. Cryphonectria parasitica (Murr.) Barr.) as a warning of the potential presence of ring shake. It is important to remark that at present there is not European standards for the grading chestnut roundwood, unlike that for other species ${ }^{9}$, nor for quality grading of standing trees. Mean diameter at $1.3 \mathrm{~m}$ of the selected ones was $26.5 \mathrm{~cm}$ (minimum 23, maximum $33 \mathrm{~cm}$ ). 18 trunks were harvested and transported to the local saw-mill and the stems were cutting into drums. The length of each log was determined taking into account the presence of defects or anomalies (e.g. large branches) and to obtain the length/diameter ratio close to 20 , between 18 and 22.50 logs were obtained with a length range between 2.4 and $4.8 \mathrm{~m}$, mean diameter $21.5 \mathrm{~cm}$ (minimum 15, maximum $32 \mathrm{~cm}$ ). A protocol similar to the previous one was applied to the logs, considering also the presence/ absence of ring shake and other possible defects, visible on the ends of the logs.

The sawing pattern has been studied to extract squared edge logs but with wide wanes which characterise the UF-beams. As the logs were tapered and the sawn faces are straight and parallel, the changeful dimensions of the wanes were biggest into the top end (minimum diameter) of the log. After the saw-mill operations the beams were transported into the Laboratory for the following tests.

The sample of beams was subjected to a sequence of tests having the aim of: I) visually grading the beams by means of an ad hoc strength grading rule, II) measuring the bending Modulus of Elasticity (MOE), III) determining the bending strength (modulus of Rupture - MOR), IV) determining the density, V) measuring the moisture content (M.C.). Finally VI) the physical and mechanical properties II, III and IV, referring to the selected grade (I) were used to derive the characteristic values (modulus of elasticity - $E_{0 \text {,mean }}$, bending strength $-f_{\mathrm{k}}$, density - $k$,) and then to determine the possible Strength Class. ${ }^{4}$

Grading: the strength grading of each timber elements is needful for the structural use; ${ }^{10}$ visual or machine grading are acceptable; in the visual grading the strength determining defect is the worst defect of the beam, according to the appropriate visual strength grading rule. In this research a visual strength grading rule was adopted: it was derived by the international document Common Understanding of Assessment Procedure (CUAP) n. 03.24/22 ${ }^{6}$ (for spruce, fir, larch and chestnut) and by the standard UNI 11035-3:2010 (only for spruce and fir). The two rules converge in a unique grade named $\mathrm{C}$, except for the possibility to grade also beams with ring shake defect, accepted for chestnut. The main discriminating defects in this visual strength grading rule, very easy to apply according to the above mentioned standards, were:

- knots dimension (maximum value of the ratio between minimum diameter of the worst knot and the thickness of the beam on which it appears),

visible ring shake, permitted only on the ends, centred and with a diameter lesser than $1 / 3$ of the minimum side of the cross section,

the fissures passing through the thickness, permitted only at the ends, with a limited length,

the slope of grain as general grain direction referring to the longitudinal axis of the beam. Each beam was graded and mechanical properties were determined according to standard EN $408^{11}$ by means of Metro-COM universal testing machine.

Elasticity: the MOE values were determined in a four-points bending test. During the loading tests the neutral axis displacement were measured by means of LVDT transducers and acquired, together with the applied load, with a Measurement Computing 16-bit DAQ connected to a PC. Small steel plates, of length not greater than one-half of the depth of the test piece were inserted between the beam and the loading heads or supports, to minimize local indentation.

Bending strength: after the MOE determination the logs where tested at failure in order to calculate the MOR (according to the EN 408), adopting the same testing geometry. The critical section (the weakest portion of the beam) was positioned inside the inner load points in four-points bending test, where the bending moment is constant, for the correct determination of the MOR value, as set by standard EN $384: 2005 .{ }^{12}$ Some of the UF-beams after the bending to failure are visible in Figure 1.

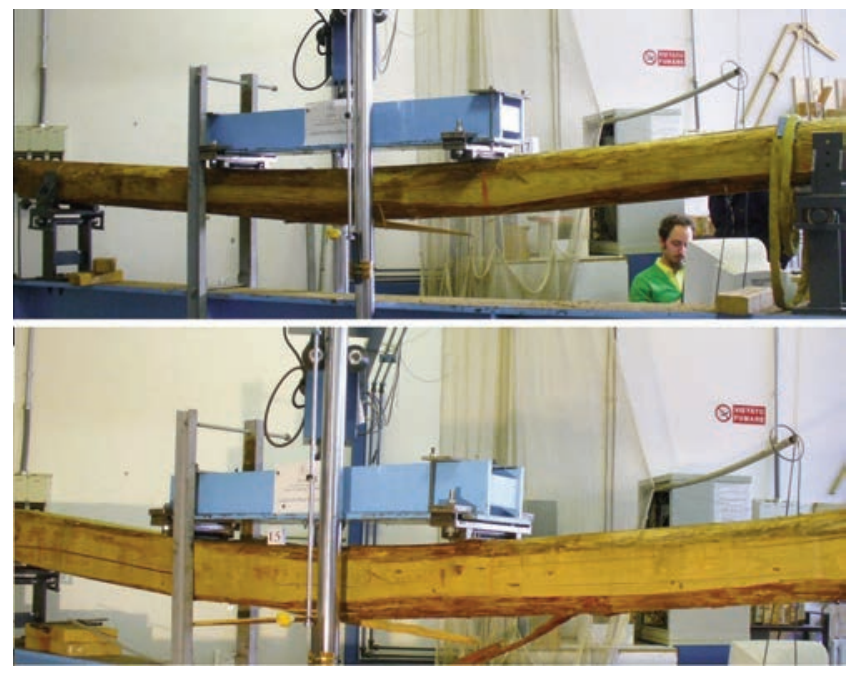

Figure 1. Two tested UF-beams after failure in bending: $n .17 \mathrm{a}$ (top of the figure), nominal cross section $220 \times 210 \mathrm{~mm}$, length $4670 \mathrm{~mm}$, MOR 39.3 MPa; n. 15a (bottom of the figure) nominal cross section $240 \times 240 \mathrm{~mm}$, length $4640 \mathrm{~mm}$, MOR 32.4 MPa. 
Density and moisture content: after the bending tests, close to the point of rupture, two adjacent specimens (corresponding to the whole cross section of each log) were collected, for the M.C. and density determination. One specimen was used for the M.C. determination adopting the double weighing method. ${ }^{13}$ The density have a great importance for timbers, because it affects their mechanical properties and it is related to the M.C., so the second specimen was used to calculate the density at the time of test (as the weight to volume ratio). After that, it has been seasoned and the density was recalculated and corrected to $12 \%$ M.C. according to the ISO $3131,{ }^{14}$ for further comparisons.

Derivation of characteristic values: to characterise timber for structure it is necessary to derive the characteristic values, starting from the ones achieved by the physical and mechanical tests. The adjustment and derivation procedures are rigorously indicated in the standard. ${ }^{12}$ The density and elasticity values must be adjusted taking into account the M.C.; the bending strength has to be standardised on the actual depth of the beams. Due to the small dimension of the sample (43 beams in 1 only group, the grade $\mathrm{C}$ ), it was decided to derogate the standard $^{12}$ and not to apply the adjusting factor $k_{\mathrm{s}}$ for the number of specimens. The choice is justified by the need to make comparison with existing characteristic values, derived from different samples.

\section{Results and discussion}

Through the sawmill operations, 49 UF-beams were achieved. One $\log$ was rejected for hard damage during handling. The yield of the sawmill operations was close to $70 \%$, a high value thank to the geometrical characteristics of the assortment. The cross sections of the beams, close to square with approximately central pith, were in the range between 120x120 mm and 240x240 mm; "squared cross section" must be conceived as the circumscribed square. The geometrical features of the sample were distributed as described in Table 1.

According to the visual strength grading rule adopted, the UF-beams graded into the grade $C$ had a very high yield: 43 beams on $49(=88 \%)$; only 6 beams $(=12 \%)$ were rejected because not grading for structure by the rule. Main reasons of rejection were: ring shake ( 1 beam), knot dimension ( 1 beam), anomaly (double pith, 1 beam), passing through fissures ( 3 beams).

No relationship were founded among the strength quality of the beams (grade $\mathrm{C}$ or rejected) and the defects and other characteristics measured on roundwood (trunks and logs), except for 2 events (the anomalies of double pith and ring shake, recorded on roundwood). The grade determining defects "fissures passing through" could not be recorded because their opening is typically delayed due to the seasoning of wood and to the increasing of the internal stress; the values of the ratio between largest branch and stem diameters at the insertion point did not have any relationship with the grade and, successively, with stiffness and strength data.

The main physical and mechanical properties obtained by tests and measures performed, are reported in Table 2.

M.C. resulted very high, as expected from chestnut large cross section beams. The very low permeability of chestnut heartwood is well known: ${ }^{15}$ a natural seasoning of such a timber members needs more than 1 warm season to reach a M.C. lower than $20 \%$ (reference value in Italian standard ${ }^{5}$ ). The high M.C. had a reduction effect on MOE so that the average MOE resulted lower than values at normal condition (corresponding to $12 \%$, reference value of the moisture of wood at the standard environment of $20 \pm 2^{\circ} \mathrm{C}$ and $65 \pm 5 \%$ relative humidity) though the adjusting factor ${ }^{12}$ was applied: it can adjust only for a M.C. difference of $6 \%$. The M.C. values had not sensible effects on MOR because on full size timber the defects outweighed any repercussion of the moisture. From the MOE, MOR and density data, were derived the characteristic values concerning the sub-sample of the 43 UF-beams selected in the Grade $\mathrm{C}$. These derivations were done to obtain comparable values for chestnut and it differs from the procedures for the definitive characteristic values for structural timber which require much more specimens. All the data of the whole sub-sample were utilized for the derivations of the MOR characteristic value $\left(f_{\mathrm{k}}\right)$, including also logs failed outside the middle third. The final values for the selected 43 beams in Grade $\mathrm{C}$ were

- characteristic density: $\quad \rho_{\kappa} 508 \mathrm{~kg} / \mathrm{m}^{3}, \mathrm{~kg} / \mathrm{m}^{3}$,

- characteristic modulus of elasticity: $E_{0, \text { mean }} 10,3 \mathrm{GPa}$

- characteristic bending strength: $\quad f_{m, k} 28,5 \mathrm{MPa}$.

These results match the Strength Class D244, the same Class for Italian chestnut structural timber with rectangular cross section ${ }^{3}$, although the characteristic value of modulus of elasticity of Italian chestnut, as stated by the standard ${ }^{16}\left(\rho_{\mathrm{\kappa}} 485 \mathrm{~kg} / \mathrm{m}^{3}, E_{0, \text { mean }} 12,5 \mathrm{GPa}, f_{m, k}\right.$ $28,0 \mathrm{MPa}$ ), is $\sim 20 \%$ higher than the present one, due to the green condition of the testing sample (M.C. $=48 \%$, much higher than wood in normal condition).

Table 1. Main geometrical features of UF-beams* sample.

\begin{tabular}{lccc}
$\begin{array}{l}\text { Depth class } \\
{[\mathrm{mm}]}\end{array}$ & Number & $\begin{array}{c}\text { Average } \\
\text { cross sections } \\
\text { depth } \mathrm{x} \text { width [mm] }\end{array}$ & $\begin{array}{c}\text { Average length } \\
{[\mathrm{mm}]}\end{array}$ \\
\hline 140 & 4 & $125 \times 123$ & 3190 \\
160 & 16 & $151 \times 151$ & 2888 \\
\hline 180 & 13 & $179 \times 177$ & 3456 \\
200 & 10 & $197 \times 195$ & 3763 \\
\hline 220 & 4 & $214 \times 211$ & 4278 \\
240 & 2 & $235 \times 225$ & 5030 \\
\hline Total sample & 49 & - & - \\
mean [mm] & - & $174 \times 173$ & 3443 \\
minimum [mm] & - & $120 \times 120$ & 2430 \\
\hline maximum [mm] & - & $240 \times 240$ & 5420 \\
dev. stand. [mm] & - & $27 \div 28$ & 608 \\
\hline C.V. [\%] & - & $16 \div 18$ & 17.7 \\
\hline
\end{tabular}

*UF-beams: "Uso Fiume" beams.

Table 2. Main data of the physical and mechanical properties.

\begin{tabular}{lcccc} 
& $\begin{array}{c}\text { M.C.* } \\
{[\%]}\end{array}$ & $\begin{array}{c}\text { Density } \\
{\left[\mathrm{kg} / \mathrm{m}^{3}\right]}\end{array}$ & $\begin{array}{c}\text { MOE }^{\text {os }} \\
{\left[\mathrm{kN} / \mathrm{mm}^{2}\right]}\end{array}$ & $\begin{array}{c}\mathrm{MOR}^{*} \\
{\left[\mathrm{~N} / \mathrm{mm}^{2}\right]}\end{array}$ \\
Mean & 48 & 571 & 10.34 & 38.5 \\
Minimum & 23 & 485 & 8.34 & 22.5 \\
\hline Maximum & 74 & 735 & 14.20 & 54.7 \\
Dev. stand. & 11.8 & 49.0 & 1.27 & 6.8 \\
\hline C.V. & $24.6 \%$ & $8.6 \%$ & $12.2 \%$ & $17.5 \%$
\end{tabular}

*Moisture content, ${ }^{\circ}$ Modulus of Elasticity, "Modulus of Rupture. \$values adjusted to the reference moisture content $12 \%$. 


\section{Conclusions}

The research presented showed that from an ordinary coppice forest of chestnut, sampled in Liguria Region, through basic saw mill operation, it is possible to obtain a very performing structural material: the assortment UF-beams. This kind of product summarises by itself very good properties:

- no need of pre-selection, except for straightness and dimensions,

- high sawing yield, close to 70\%,

- good grading yield: 88\% UF-beams graded for structure (Grade C),

- high structural performances, comparable to the chestnut structural timber with rectangular cross section, and selectable in Strength Class D24,

- immediately usable, without necessity to be seasoned or kiln dried.

In conclusion the large natural wanes did not have any sensible effect on mechanical performances, making UF-beams similar to the ones with rectangular cross section.

\section{References}

1. Ministero delle Politiche Agricole Alimentari e Forestali - Corpo Forestale dello Stato Consiglio per la Ricerca e la Sperimentazione in Agricoltura (CRA-MPF), 2005. INFC - L'Inventario Nazionale delle foreste e dei serbatoi forestali di Carbonio. Metodi e risultati Available from http://www.sian.it/inventarioforestale/jsp/01tabelle _superficie.jsp . Accessed: May 2013

2. Camerano P., Grieco C., Mensio F., Varese P. I Tipi forestali della Liguria, Regione Liguria, Erga Edizioni (GE): 336 pp. 2008.

3. EN (European standard). Structural Timber. Strength classes. Assignment of visual grades and species, Norm EN 1912:2012. Brussels, Belgium. European Committee for Standardization, 2012.

4. EN (European standard). Structural timber. Strength classes. Norm EN 338:2009. Brussels, Belgium. European Committee for Standardization, 2009.

5. UNI (Italian standard). Legno strutturale - Classificazione a vista dei legnami secondo la resistenza meccanica - Parte 3: Travi Uso Fiume e Uso Trieste. Norm UNI 11035-3:2010. Milano, Italia. Ente Italiano di Unificazione, 2010.
6. Österreichisches Institut für Bautechnik, 2012. Strength graded structural timber - square edged logs with wane. Common Understanding of Assessment Procedure CUAP 03.04/22. OIB, Vienna, Austria.

7. Ranta-Maunus A. et al., 1999. Round small diameter timber for construction. Final report of project FAIR CT 95-0091. VTT, publication 383 pp:191+19. Espoo, Finland

8. Österreichisches Institut für Bautechnik, 2013. Uso Fiume of chestnut. Strength graded structural timber - Squared edge logs with wane to be used as structural element in buildings and civil engineering works. European Technical Approval ETA-12/0540. EOTA European Organization for Technical Approvals. OIB, Vienna, Austria.

9. EN (European standard). Hardwood round timber. Qualitative classification. Part 1: Oak and beech. Norm EN 1316-1:2013. Brussels, Belgium. European Committee for Standardization; 2013.

10. Italian regulation: 2008. Nuove Norme Tecniche per le Costruzioni. DM 14/01/2008. In G.U. n. 29 4/02/2008 - S.0. n. 30

11. EN (European standard). Timber structures. Structural timber and glued laminated timber. Determination of some physical and mechanical properties. Norm EN 408:2010. Brussels, Belgium. European Committee for Standardization; 2010.

12. EN (European standard). Structural timber. Determination of characteristic values of mechanical properties and density. Norm 384:2005. Brussels, Belgium. European Committee for Standardization; 2005.

13. EN (European standard). Moisture content of a piece of sawn timber. Determination by oven dry method. Norm 13183-1:2002. Brussels, Belgium. European Committee for Standardization; 2002.

14. ISO (International Organization for Standardization). Wood Determination of density for physical and mechanical tests. Norm ISO 3131:1975. Geneva: International Organization for Standardization Publications; 1975.

15. Giordano G., Tecnologia del legno. Vol. $3^{* *}$, II edition. Torino, Italy: UTET; 1988.

16. UNI (Italian standard). Legno strutturale - Classificazione a vista dei legnami secondo la resistenza meccanica - Parte 2: Regole per la classificazione a vista secondo la resistenza meccanica e valori caratteristici per tipi di legname strutturale. Norm UNI 110352:2010. Milano, Italia. Ente Italiano di Unificazione, 2010. 